\title{
Unilateral Subfrontal Approach for Giant Olfactory Groove Meningiomas
}

\author{
Waleed Abbass, Mohamed Adel Ghoneim* \\ Department of Neurosurgery, Faculty of Medicine, Cairo University, Cairo, Egypt \\ Email: *madel1981@hotmail.com
}

How to cite this paper: Abbass, W. and Ghoneim, M.A. (2020) Unilateral Subfrontal Approach for Giant Olfactory Groove Meningiomas. Open Journal of Modern Neurosurgery, 10, 175-181. https://doi.org/10.4236/ojmn.2020.101018

Received: December 21, 2019

Accepted: January 18, 2020

Published: January 21, 2020

Copyright $\odot 2020$ by author(s) and Scientific Research Publishing Inc. This work is licensed under the Creative Commons Attribution International License (CC BY 4.0).

http://creativecommons.org/licenses/by/4.0/

(c) (i) Open Access

\begin{abstract}
Objective: Many approaches have been used for surgical removal of olfactory groove meningioma (OGM) as pterional, bifrontal, interhemispheric, and frontolateral approach. We evaluated the role of unilateral subfrontal approach for the removal of giant OGM "bigger than 6-cm". Patients and Methods: Nine patients with giant OGM had unilateral subfrontal approach between $1^{\text {st }}$ of January 2015 and December 2017 in Cairo University Hospitals. A retrospective study we done analyzing clinical data, neuroimaging, surgical result and extent of tumor resection. Results: Total tumor resection was achieved in seven cases "Simpson grade I and II". Subtotal resection was achieved in two cases, one case there was enchasing of the anterior cerebral artery. The other case subtotal resection was achieved due to old age of the patient. The frontal air sinus and cribriform plate and ethmoidal sinus were repaired using fat, fascia lata and vascularized pericranium flab with the use of histoacryl: One case developed hydrocephalus which required the insertion of a ventriculo-peritoneal shunt. One case developed wound infection and meningitis which required medical treatment only. There is no case of CSF leak or mortality in our series. Conclusion: The unilateral subfrontal approach is a safe and efficient approach for removal of giant olfactory groove meningioma. It combines the benefits of the bifrontal, frontolateral and pterional approach with early access to CSF drainage and early attack of the blood supply of the tumor.
\end{abstract}

\section{Keywords}

Olfactory Groove Meningioma, Subfrontal Approach, CSF Leakage

\section{Introduction}

OGM arises from the ethmoidal cribriform plate and it accounts for approximately “9\% - 12\%" of intracranial tumors [1] [2] [3] [4]. 
They usually arise from the midline and may extend to the ethmoidal sinuses in $15 \%$ of cases [5]. It may also extend the nasal cavity and orbit. Its blood supply derives from the anterior and posterior ethmoidal arteries, meningeal branches of ophthalmic artery [6]. As the tumor reaches a big size it may have blood supply from anterior cerebral artery and anterior communicating artery [7].

Many approaches have been used by different surgeons as bifrontal, pterional, interhemispheric and supraorbital approaches have been used [8] [9].

The goal of this study is to evaluate the safety and efficacy of unilateral subfrontal approach for removal of giant olfactory groove meningiomas as regarding the degree of removal, clinical outcome, histopathology, follow-up period and imaging studies.

\section{Patients and Methods}

Nine patients with giant OGM (midline anterior cranial fossa from the ethmoidal cribriform plate and more than $6 \mathrm{~cm}$ ) all the patients had clinical examination, laboratory, and imaging in form of Computerized tomography (CT) and Magnetic resonance imaging (MRI).The patients were operated upon in Cairo University Hospitals between $1^{\text {st }}$ of January 2015 and December 2017, Cairo, Egypt, using unilateral subfrontal approach (Figure 1, Figure 2). There were seven females (77.7\%) and two males (22.3\%), with age ranging from 25 to 73 years old with mean age 49 years.

\section{Technique of unilateral subfrontal approach:}

The approach was performed on the right side in all cases, the patient is placed in supine position with the head fixed by Mayfield holder in neutral position. The
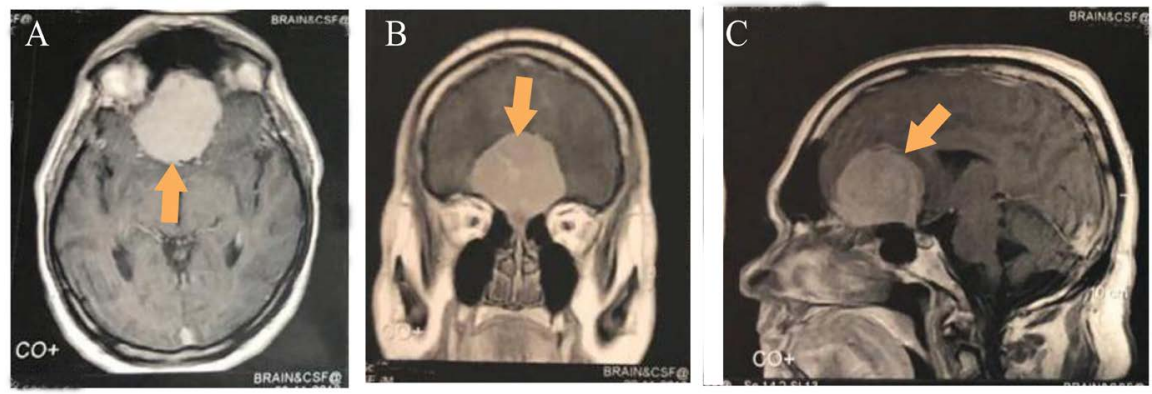

Figure 1. Preoperative MRI axial, coronal, and sagittal with contrast showing giant OGM.
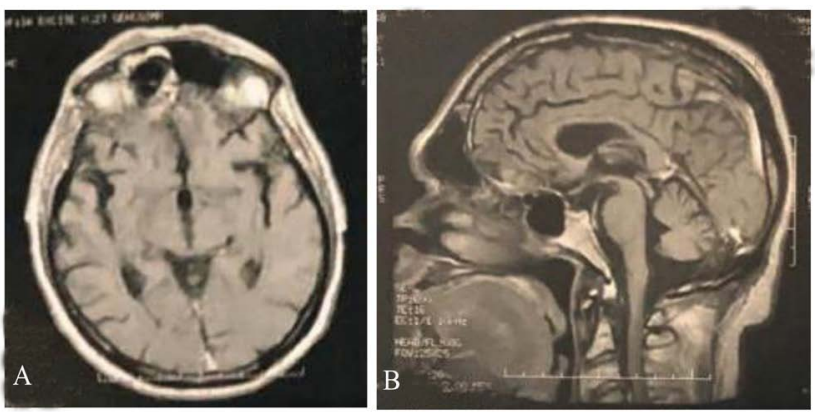

Figure 2. Postoperative MRI with contrast showing total removal of OGM. 
neck extended with the head elevated above level of heart for adequate venous drainage and to avoid excessive retraction on the frontal lobe.

A semi-coronal incision behind the hair was made; a vascularized pericranium flap is prepared. A burr-hole was placed just posterior to the anterior temporal line and small $4-\mathrm{cm} \times 4-\mathrm{cm}$ rectangular or triangular bone flap reaching to the midline flush with the anterior cranial base.

When the frontal air sinus is opened, great attention is taken to remove the whole mucosa and is packed with fat and gelfoam soaked with betadine. The sphenoid ridge is drilled.

The dura is opened in a linear fashion flushed with the base. Drainage of cerebrospinal fluid (CSF) by opening the sylvian fissure and the optico-carotid cistern to avoid excessive retraction on the frontal lobe. This provides a more medial view of the frontobasal region.

Identification of the ipsilateral internal carotid, anterior cerebral artery and ipsilateral optic nerve.

Devascularization of the tumor at the base, the tumor capsule is opened and internal debulking is done using Cavetron ultrasonic Aspirator.

After maximum internal debulking the tumor is dissected from ipsilateral $A_{1}$, contralateral $\mathrm{A}_{1}$ and anterior communicating artery. Cauterization of the dura of the base and removing it, if there is hyperostosis the bone is drilled.

Repair of the anterior cranial base is one of the most important steps in olfactory groove meningioma surgery. We repair the base using three layers.

- $1^{\text {st }}$ layer: By autolysis fat fixed to the base by histoacryl.

- $2^{\text {nd }}$ layer: By fascia lata, we sutured the upper edge of the fascia lata to the anterior edge of the dura and the lower edge is put onlay on the anterior cranial base and fixed by histoacryl.

- $3^{\text {rd }}$ layer: By vascularized pericranium flap, where the lower edge is put onlay on the base and fixed by histoacryl.

Then the vascularized pericranium flap is sutured to the posterior edge of the dura.

All the patients were operated upon after departmental ethical committee approval.

\section{Results}

The most common presenting symptom (Table 1):

- Mental disturbance (dementia, memory affection, depression) was founded in six out of nine patients (66.6\%).

- Headache was found in nine out of nine patients (100\%).

- Visual disturbance was founded in one out of nine patients (11.1\%).

- Seizure was founded in two out of nine patients (22.2\%).

- Anosmia was founded in seven out of nine patients (77.7\%).

\section{Radiological features:}

Bony hyperostosis CT was found in three patients (33.3\%), tumor calcification in two patients (22.2\%), and compression of optic nerve in MRI one patient 
(11.1\%). Tumor extension in paranasal sinuses was found in two patients (22.2\%). Peritumoral edema was found in six patients (66.6\%). Tumor diameter ranges from $6-12 \mathrm{~cm}$ with a mean diameter $9-\mathrm{cm}$.

According to Simpson classification, total removal (grade I, II) was achieved in seven patients $(77.7 \%)$.

Subtotal removal grade III and IV was achieved in two patients (22.2\%), where one patient the anterior cerebral was enchased by the tumor, the other case the patient was 73 years old so minimal procedure was required (Table 2).

We have one case of wound infection and meningitis which was treated medically by antibiotic (11.1\%).

One patient (11.1\%) developed hydrocephalus which required the insertion of ventriculo-peritoneal shunt.

We have no cases of cerebrospinal fluid (CSF) leakage in our series.

Postoperative seizures occurred in one patient (11.1\%) which was controlled by antiepileptic drugs.

Intraoperative frontal polectomy was needed in two patients (22.2\%) (Table 3).

Table 1. Manifesting symptoms of olfactory groove meningioma.

\begin{tabular}{ccc}
\hline \multicolumn{2}{c}{ Olfactory groove meningioma $(\mathbf{n}=\mathbf{9})$} & \multicolumn{2}{c}{ Clinical presentation } \\
\hline Percentage & No. of patients & Headache \\
$100 \%$ & 9 & Anosmia \\
$77.7 \%$ & 7 & Mental disturbance (dementia, \\
$66.6 \%$ & 6 & memory affection, depression) \\
22.25 & 2 & Seizure \\
$11.1 \%$ & 1 & Visual disturbance
\end{tabular}

Table 2. Extent of tumor removal.

\begin{tabular}{ccc}
\hline \multicolumn{2}{c}{ Extent of tumor removal (Simpson classification) } & Clinical presentation \\
\cline { 1 - 2 } Percentage & No. of patients & \\
\cline { 1 - 2 } $77.7 \%$ & 7 & Total removal (grade I and II) \\
$22.2 \%$ & 2 & Subtotal removal (grade III and IV) \\
\hline
\end{tabular}

Table 3. Postoperative complications.

\begin{tabular}{|c|c|c|}
\hline \multicolumn{2}{|c|}{ Postoperative complications } & \multirow{2}{*}{ Clinical presentation } \\
\hline Percentage & No. of patients & \\
\hline $11.1 \%$ & 1 & Wound infection and meningitis \\
\hline $11.1 \%$ & 1 & Developed hydrocephalus \\
\hline $0.0 \%$ & 0 & Cerebrospinal fluid (CSF) leakage \\
\hline $11.1 \%$ & 1 & Postoperative seizures \\
\hline $22.2 \%$ & 2 & Intraoperative frontal polectomy \\
\hline
\end{tabular}


Histopathological examination revealed meningiothelial meningioma in seven cases (77.7\%) (Figure 3), one patient (11.1\%) psammomatous and one patient (11.1\%) fibrous type.

During the follow-up period which ranges from 6 months to 3 years we don't have any recurrent cases.

The two cases in which there is residual are followed-up regularly and needs no more intervention.

\section{Discussion}

Surgical resection of giant olfactory groove meningiomas (larger than $6 \mathrm{~cm}$ ) is very challenging. Despite the large size of these tumors at the time of operation gross total resection was achieved in seven out of nine patients $(77.7 \%)$ due to intact arachnoid plane between the tumor and neurovascular structures.

In comparison is the series of olfactory groove meningiomas operated by Hentschel et al. [1] eleven cases were operated and they were all totally removed. Two patients with subtotal removal and they were recurrent cases.

In comparison with the series olfactory groove meningioma operated by $\mathrm{Na}$ kamura et al. [2] he found that the rate of tumor removal is not affected by the approach. The rate of tumor removal Simpson grade I and II was $92.7 \%$ using frontal lateral approach and $91.2 \%$ using the frontal approach.

In the series olfactory groove meningiomas operated by Khaled El-Bahy [10] total removal Simpson grade I and II was achieved in $77.8 \% 14$ from 18 cases, subtotal removal was achieved in four patients (22.2\%).

In our series total removal was achieved seven out of nine patients $(77.7 \%)$ although unilateral subfrontal approach does not have varies use as by frontal approach we achieved high rate of tumoral resection.

Cerebrospinal fluids (CSF) leakage is a major problem regarding tumors of the anterior skull base especially giant olfactory groove meningioma.

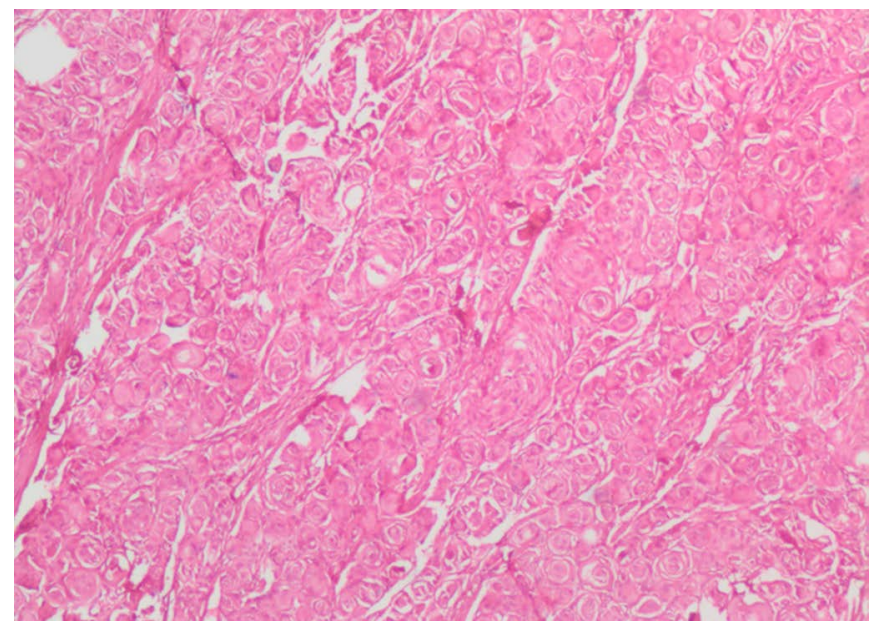

Figure 3. Histopathological examination revealed meningiothelial meningioma with lobulated architecture, often contain "meningothelial" whorls Syncytial cells with indistinct cell membranes original magnification $\times 40$. 
In our study we do not have any case of CSF leakage after surgery as we used three layers for reconstruction of the skull base.

In the comparison with the series of Ciurea et al. [11] which is a retrospective study 59 cases he have seven cases with CSF leakage a related mainly to tumors with Simpsons grade I removal and tumor invasion of the ethmoid bone, conservative treatment in the form of bed rest, fluid restriction and lumbar puncture twice daily, the CSF leakage stopped in all cases.

In comparison with the series of Khaled El-Bahy [10] which included in 18 cases, 3 out of $18(16.7 \%)$ patients developed CSF leak which responded to medical treatment and repeated lumbar puncture.

The rate of tumor recurrence for olfactory groove meningiomas in literature is $0 \%-41 \%$ with follow-up period $3.7-25$ years by Nakamura et al. [2].

In the series of Nakamura et al. [2] which included 1800 cases, the recurrent rate was $4.9 \%$ with a mean follow-up period 5.3 years. The recurrent rate in patients with bifrontal approach was $6.5 \%$ and in patients with frontal lateral approach was $2.9 \%$.

In our series we do not have recurrent cases due to short period of follow-up which ranges from 6 months to three years.

In the series of Ciurea et al. [11] the rate of recurrent cases was $10.1 \%$ (6 patients) with mean 7.2 years follow-up.

In the series of Hentschel et al. [1] which included 13 cases there is no recurrence with a mean follow-up period 2 years.

In our series the mental disturbance (dementia, memory affection, and depression) was found in six patients (66.6\%), postoperatively five patients improved.

One patient developed hydrocephalus (11.1\%) in the fifth postoperative day and required the insertion of ventriculoperitoneal shunt. One patient developed wound infection and meningitis which was treated conservatively.

In the series of Nakamura et al. [2] hydrocephalus developed in two patients (5.8\%).

In our series we have two patients with seizures preoperatively, only one patient developed seizure (11.1\%), which was controlled by antiepileptic drugs.

In comparison with Nakamura et al. [2] four patients developed seizures postoperatively (11.8\%), which was controlled by antiepileptic drugs.

The need for frontal polectomy was needed in two patients $(22.2 \%)$ due to increase of intracranial pressure.

In our series we have seven cases with anosmia (77.7\%) which did not improve postoperatively.

\section{Conclusions}

The unilateral subfrontal approach is a safe and efficient approach for removal of giant olfactory groove meningioma. It combines the benefits of the bifrontal, frontolateral and pterional approach with early access to CSF drainage and early 
attack of the blood supply of the tumor.

Failure of total removal of the tumor due to enchasing of the anterior cerebral artery by the tumor is not related to the approach but mainly due to absence of arachnoid plane between the tumor and the anterior cerebral artery.

\section{Conflicts of Interest}

The authors declare no conflicts of interest regarding the publication of this paper.

\section{References}

[1] Hentschel, S.J. and Demonte, F. (2003) Olfactory Groove Meningiomas. Neurosurg Focus, 14, Article 4. https://doi.org/10.3171/foc.2003.14.6.4

[2] Nakamura, M., Struck, M., Roser, F., Vorkapic, P. and Samii, M. (2007) Olfactory Groove Meningiomas: Clinical Outcome and Recurrence Rates after Tumor Removal through the Frontolateral and Bifrontal Approach. Neurosurgery, 60, 844-852. https://doi.org/10.1227/01.NEU.0000255453.20602.80

[3] Tuna, H., Bozkurt, M., Ayten, M., Erdogan, A. and Deda, H. (2005) Olfactory Groove Meningiomas. Journal of Clinical Neuroscience, 12, 664-668.

https://doi.org/10.1016/j.jocn.2005.05.002

[4] Welge-Luessen, A., Temmel, A., Quint, C., Moll, B., Wolf, S. and Hummel, T. (2001) Olfactory Function in Patients with Olfactory Groove Meningioma. Journal of Neurology, Neurosurgery, and Psychiatry, 70, 218-221. https://doi.org/10.1136/jnnp.70.2.218

[5] DeMonte, F. (1996) Surgical Treatment of Anterior Basal Meningiomas. Journal of Neuro-Oncology, 29, 239-248. https://doi.org/10.1007/BF00165654

[6] Mayfrank, L. and Gilsbach, J.M. (1996) Interhemispheric Approach for Microsurgical Removal of Olfactory Groove Meningiomas. British Journal of Neurosurgery, 10, 541-545. https://doi.org/10.1080/02688699646835

[7] Ojemann, R.G. (1991) Olfactory Groove Meningiomas. In: Al-Mefty, O., Ed., Meningiomas, Raven Press, New York, 383-393.

[8] Obeid, F. and Al-Mefty, O. (2003) Recurrence of Olfactory Groove Meningiomas. Neurosurgery, 53, 534-543. https://doi.org/10.1227/01.NEU.0000079484.19821.4A

[9] Spektor, S., Valarezo, J., Fliss, D.M., Gil, Z., Cohen, J., Goldman, J. and Umansky, F. (2005) Olfactory Groove Meningiomas from Neurosurgical and Ear, Nose, and Throat Perspectives: Approaches, Techniques, and Outcomes. Neurosurgery, 57, 268-280. https://doi.org/10.1227/01.NEU.0000176409.70668.EB

[10] El-Bahy, K. (2009) Validity of the Frontolateral Approach as a Minimally Invasive Corridor for Olfactory Groove Meningiomas. Acta Neurochirurgica, 151, 1197-1205. https://doi.org/10.1007/s00701-009-0369-3

[11] Ciurea, A.V., Iencean, S.M., Rizea, R.E. and Brehar, F.M. (2012) Olfactory Groove Meningiomas. A Retrospective Study on 59 Surgical Cases. Neurosurgical Review, 35, 195-202. https://doi.org/10.1007/s10143-011-0353-2 